\title{
The Effect of PCM Capsule Material on the Thermal Energy Storage System Performance
}

\author{
R. Meenakshi Reddy, ${ }^{1}$ N. Nallusamy, ${ }^{2}$ and K. Hemachandra Reddy ${ }^{3}$ \\ ${ }^{1}$ Department of Mechanical Engineering, Sri Venkateswara Institute of Technology, Anantapuram 515722, India \\ ${ }^{2}$ Department of Mechanical Engineering, Sri Sivasubramaniya Nadar College of Engineering, Chennai 603110, India \\ ${ }^{3}$ JNTU College of Engineering, Anantapuram 515722, India
}

Correspondence should be addressed to R. Meenakshi Reddy; rmreddy123@gmail.com

Received 31 August 2013; Accepted 5 December 2013; Published 21 January 2014

Academic Editors: Z. Oktay and R. P. Saini

Copyright (C) 2014 R. Meenakshi Reddy et al. This is an open access article distributed under the Creative Commons Attribution License, which permits unrestricted use, distribution, and reproduction in any medium, provided the original work is properly cited.

\begin{abstract}
Phase change material (PCM) based thermal energy storage (TES) systems are gaining increasing importance in recent years in order to reduce the gap between energy supply and demand in solar thermal applications. The present work investigates the effect of PCM capsule material on the performance of TES system during charging and discharging processes. The TES unit contains paraffin as PCM filled in spherical capsules and is integrated with flat plate solar collector. Water is used as sensible heat material as well as heat transfer fluid (HTF). The PCM capsules are of $68 \mathrm{~mm}$ diameter and are made using three different materials, namely, (i) high density polyethylene (HDPE), (ii) aluminum (Al), and (iii) mild steel (MS). The experimental investigation showed that the charging and recovery of stored energy are less affected by the spherical capsules material. The variables, like charging time and discharging quantity, are varied around $5 \%$ for the different capsule materials. Even though aluminum thermal conductivity is much higher than HDPE and mild steel, its influence on the performance of TES system is very low due to the very high internal heat resistance of PCM material stored in the spherical capsules.
\end{abstract}

\section{Introduction}

Solar energy is the most promising inexhaustible heat energy source for the present and future needs of mankind. Compared to the power generation from the solar energy, utilization of solar energy for moderate temperature heat applications is more efficient and economical. The increasing cost of fossil fuels in the recent years is making solar energy utilization more economical for heating applications. One of the major problems with the solar energy is its intermittent nature. So to balance the energy supply and demands, a heat energy storage system is necessary. There are three main methods of thermal energy storing systems, that is, sensible, latent, and combined sensible and latent heat storage systems. The thermal energy storage systems using both sensible and latent heat storage methods are gaining a lot of importance now a days, due to their high thermal energy storage capacity per unit volume and isothermal behavior during charging and discharging processes.
In this direction, a lot of research is going on throughout the world for improving the performance of TES systems in the recent years. Some of the important contributions related to TES system using sensible and latent heat are presented. Weislogel and Chung [1] reported the effect of condensation heat transfer in small arrays of PCM filled spheres on the charging process of TES system. Ismail and Henríquez [2] investigated both theoretically and experimentally the performance of spherical capsules as PCM containers. Stritih [3] has studied experimentally the heat transfer characteristics of a latent heat storage unit with a finned surface, in terms of the solidification and melting processes by comparing them with those of a heat storage unit with a plain surface. Shiina and Inagaki [4] studied the improvement of thermal conductivity by saturating porous metals with phase change materials. The influence of effective thermal conductivity on melting time is studied by analyzing melting characteristics of a heat storage circular capsule in which porous metal saturated with PCM is inserted. Ettouney et al. [5] studied the performance 
of thermal energy storage system filled with paraffin wax and metal beads in spherical capsules. They have shown that the heat transfer rate is increased because of placing the metal beads along with the paraffin in the capsules. Nallusamy [6] had conducted charging and discharging experiments on a combined sensible and latent heat TES system using paraffin as PCM and water as sensible heat material. Discharging experiments are conducted continuous and batchwise processes to recover the stored heat, and concluded that batchwise discharge process is best to recover the complete stored energy from the TES system. Mettawee and Assassa [7] studied the heat transfer rate from HTF to PCM by adding the aluminium powder in the paraffin wax. It was found that the charging time was reduced by approximately $60 \%$ by adding aluminum powder in the wax. El Qarnia [8] has done the numerical analysis to predict the thermal behavior and performance of a solar latent heat storage unit using various phase change materials for heating the water. The number of tubes, flow rate of water, mass of the PCM, and so on was optimized for given summer climatic conditions of Marrakech city.

The objective of the present work is to predict the best material for spherical capsules among three different materials (HDPE, Al, and MS) for better efficiency of sensible and latent heat thermal energy storage unit integrated with varying (solar) heat source. Parametric studies are carried out to examine the effects of the material and HTF flow rates on the performance of the storage unit for varying inlet fluid temperatures. For both the energy storage and recovery processes, water is used as the heat transfer fluid.

\section{Experimental Investigation}

2.1. Experimental Setup. Figures 1 and 2 show the schematic diagram and photographic view of the experimental setup developed for the investigation. The insulated thermal energy storage tank has a capacity of 51 liters $(360 \mathrm{~mm}$ diameter and $504 \mathrm{~mm}$ height) and is filled with $68 \mathrm{~mm}$ diameter spherical capsules as shown in Figure 1. The PCM used in the experiment is paraffin (melting temperature of $61 \pm 2^{\circ} \mathrm{C}$ and latent heat of fusion of $213 \mathrm{KJ} / \mathrm{Kg}$ ) and materials of the spherical capsules used in the experiments are high density polyethylene (HDPE), aluminum (Al), and mild steel (MS). The TES tank is divided into four segments; that is, at $x / L=$ $0.25,0.5,0.75$, and 1.0 ( $L$ is length of the TES tank, $\mathrm{mm} ; x$ is the axial distance from the top of the TES tank, $\mathrm{mm} ; x / L$ is the dimensionless axial distance from the top of the TES tank) along its axial direction; the resistant temperature detectors (RTDs) with an accuracy of $\pm 0.3^{\circ} \mathrm{C}$ are placed at the inlet, outlet, and four segments of the TES tank to measure the temperatures of HTF. Another four numbers of RTDs are inserted into the PCM capsules and they are placed at four segments of the TES tank to measure the temperatures of PCM. The RTDs are connected to a temperature indicator, which provides instantaneous digital outputs (Figure 1).

A flow meter with an accuracy of $\pm 2 \%$ is used to measure the flow rate of HTF and a centrifugal pump (500 lit/hour) is employed to circulate the HTF through the storage tank.

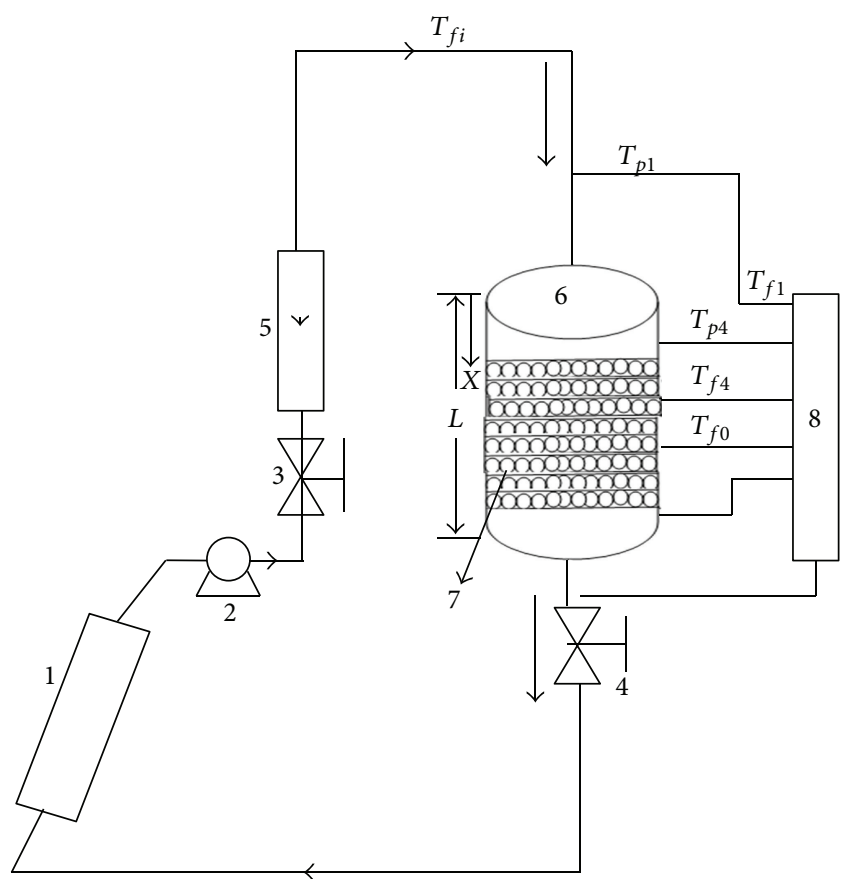

FIGURE 1: Schematic of experimental setup (1) solar flat plate collector, (2) pump, (3) and (4) flow control valves, (5) flow meter, (6) TES tank, (7) PCM capsules, and (8) temperature indicator, $T_{p}$, and $T_{f}$ : temperature sensors (RTDs).

2.2. Experimental Details. The performance of the charging of TES is studied using $2 \mathrm{lit} / \mathrm{min}, 4 \mathrm{lit} / \mathrm{min}$, and $6 \mathrm{lit} / \mathrm{min}$ flow rates with varying inlet HTF temperatures. Initially, the energy is stored inside the capsules as sensible heat until the PCM reaches its melting temperature. As the charging process proceeds, energy storage is achieved by melting the PCM at a constant temperature. Finally, the PCM becomes superheated. The energy is then stored as sensible heat in liquid PCM. Temperatures of the PCM and HTF are recorded at an interval of 12 minutes. The charging process is continued until the PCM temperature reaches the value of $70^{\circ} \mathrm{C}$.

Batchwise discharging of TES is studied with different discharge flow rates, that is, $2 \mathrm{lit} / \mathrm{min}, 4 \mathrm{lit} / \mathrm{min}$, and $6 \mathrm{lit} / \mathrm{min}$, keeping the constant cold water inlet, that is, $2 \mathrm{lit} / \mathrm{min}$ and $30^{\circ} \mathrm{C}$. A certain quantity of hot water (20 lit) is withdrawn from TES tank and the tank is again filled with cold water of quantity equal to the amount of water withdrawn. Again after a time interval of 20 minutes allowing transfer of energy from PCM to HTF, another 20 lit of water is withdrawn from the TES tank. This process is continued until the water (HTF) outlet temperature reaches $34^{\circ} \mathrm{C}$.

\section{Results and Discussions}

The temperature distributions of HTF and the PCM in the storage tank for different mass flow rates and different materials of capsules are recorded during charging and discharging processes. Table 1 shows the thermophysical properties of PCM. 


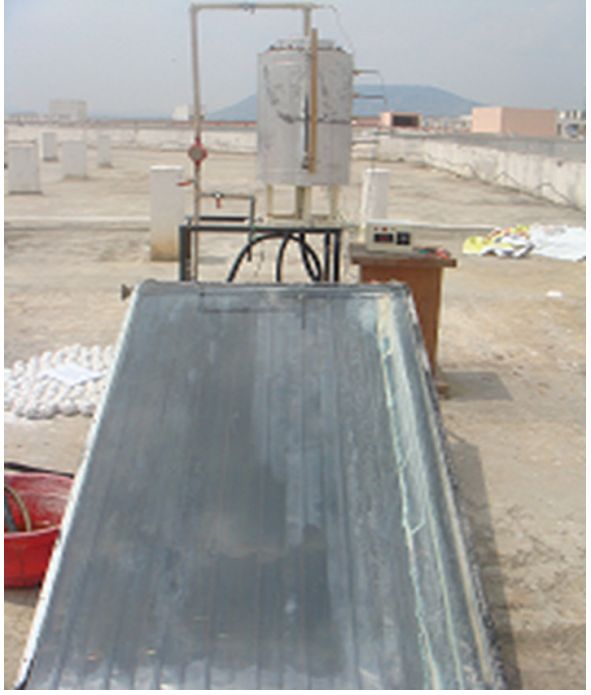

FIgURE 2: Photographic view of TES tank coupled with solar collector.

TABLE 1: Thermophysical properties of PCM.

\begin{tabular}{lc}
\hline \multicolumn{2}{c}{ Paraffin wax type $\mathrm{II}^{*}$} \\
\hline Melting temperature $\left({ }^{\circ} \mathrm{C}\right)$ & 61 \\
Latent heat of fusion $(\mathrm{kJ} / \mathrm{kg})$ & 213 \\
Density $\left(\mathrm{kg} / \mathrm{m}^{3}\right)$ solid & 861 \\
Density $\left(\mathrm{kg} / \mathrm{m}^{3}\right)$ liquid & 778 \\
Specific heat $\left(\mathrm{J} / \mathrm{kg}^{\circ} \mathrm{C}\right)$ solid & 1850 \\
Specific heat $\left(\mathrm{J} / \mathrm{kg}^{\circ} \mathrm{C}\right)$ liquid & 2384 \\
Thermal conductivity $\left(\mathrm{W} / \mathrm{m}^{\circ} \mathrm{C}\right)$ solid & 0.40 \\
Thermal conductivity $\left(\mathrm{W} / \mathrm{m}^{\circ} \mathrm{C}\right)$ liquid & 0.15 \\
\hline
\end{tabular}

Manufactures: ${ }^{*}$ Chennai Petroleum Corporation Ltd., Chennai, India.

3.1. Charging Process. The charging experiments are conducted for the combination of various parameters of mass flow rates, various materials of the spherical capsules, and HTF inlet temperature (Figure 3).

3.1.1. Temperature Histories of HTF and PCM. Figure 4(a) shows the temperature histories during charging process. This graph shows the relationship between HTF temperature and charging time in minutes. This graph shows how the temperature of HTF varies at different locations of the tank, that is, at $x / L=0.25,0.5,0.75$, and 1.0. During this experiment, the HTF is circulated between TES tank and solar flat plate collector at a flow rate of $4 \mathrm{lit} / \mathrm{min}$. The variation of inlet temperature of HTF along with the charging time is also shown in the figure. The temperature difference of HTF between $x / L=0.25$ and $x / L=1.0$ positions is very low (around $5^{\circ} \mathrm{C}$ ) over the complete charging period. It means that throughout the charging period the temperature difference between inlet HTF temperature and temperature of HTF in the tank is very low, because the heat absorption rate of HTF from the solar flat plate collector is very low. The charging period is around $270 \mathrm{~min}$ (from $10.00 \mathrm{AM}$ to $2.30 \mathrm{PM}$ ). It is a long period to absorb

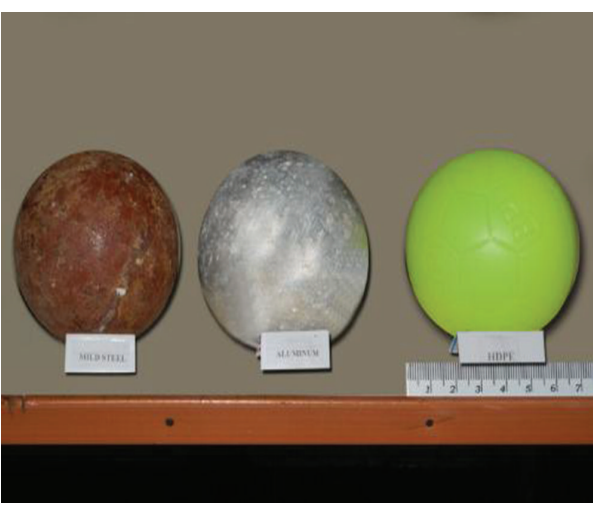

Figure 3: Photograph view of different materials of spherical capsules.

the sufficient solar radiation $(10,000 \mathrm{KJ})$ to charge the TES tank. It means that if we increase the surface area of flat plate collector proportionately, the temperature difference between inlet HTF and stored HTF increases correspondingly, in turn the charging time will be decreased proportionately. Figure 4(b) represents PCM temperature and charging time. The different curves show the variation of PCM temperature at different locations during the complete charging period. Figures 4(a) and 4(b) show the same trend at all the locations of the TES tank. By observing Figures 4(a) and 4(b), very low temperature difference is maintained between HTF and PCM temperatures till the PCM temperature reaches $60^{\circ} \mathrm{C}$. After that, even though HTF temperature is increased, the PCM temperature is not increased due to the melting process of PCM in the capsule. After completion of the melting process, the PCM temperature is increased to $70^{\circ} \mathrm{C}$.

Figure 4(c) shows the variation of HTF inlet temperatures, temperatures of HTF in the tank, and PCM temperatures at segment $2(x / L=0.5)$ along with charging time. The temperatue difference between HTF and PCM temperatures is very low till the $60^{\circ} \mathrm{C}$ of PCM. It is because of the slow heating rate of HTF at solar flat plate collector and comparatively high heat transfer rate between HTF and PCM. The temperature difference between HTF and PCM is found around $5^{\circ} \mathrm{C}$ during melting process, that is, $61^{\circ} \mathrm{C}$. After the melting process, again the temperature difference between HTF and PCM is narrowed. The HTF inlet temperature throughout the charging process is slightly more than HTF and PCM temperatures.

3.1.2. Effect of HTF Mass Flow Rates. Figure 5 illustrates the effect of the varying mass flow rates of $\operatorname{HTF}(2,4$, and 6 lit/min) during the charging of the storage tank for the varying HTF inlet temperatures. The graphs show that there is an effect of the mass flow rate of HTF on the charging time, that is, around $10 \%$ less time for $6 \mathrm{lit} / \mathrm{min}$ mass flow rate compared to $2 \mathrm{lit} / \mathrm{min}$ flow rate. Throughout the charging period, the heat transfer rate from HTF to PCM is a little bit higher for $6 \mathrm{lit} / \mathrm{min}$ HTF flow rate compared to 2 and $4 \mathrm{lit} / \mathrm{min}$ flow rates. It means that the absorption of heat from the solar flat plate collector and transferring the same heat to TES tank 


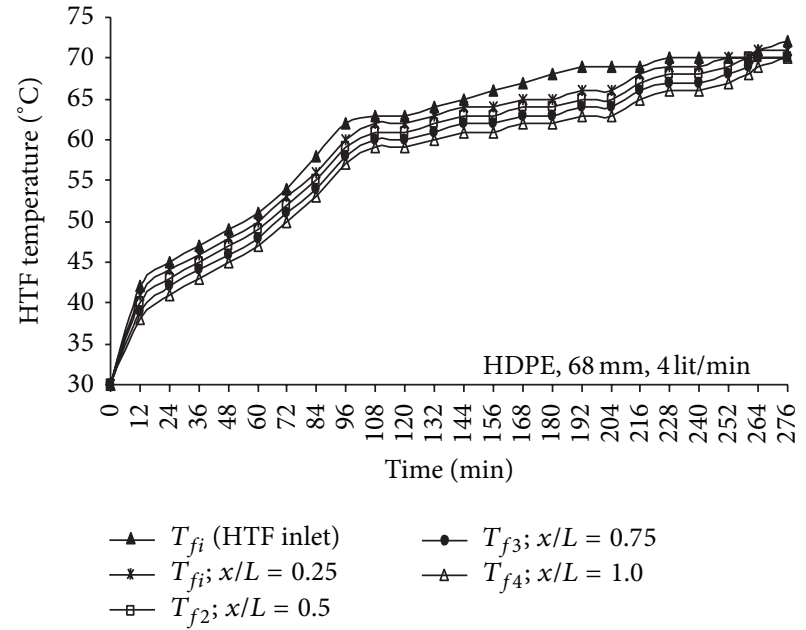

(a)

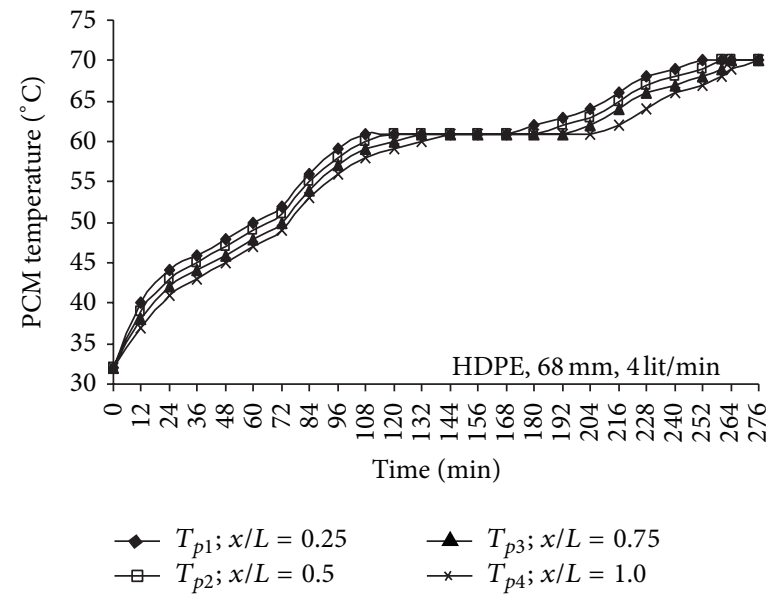

(b)

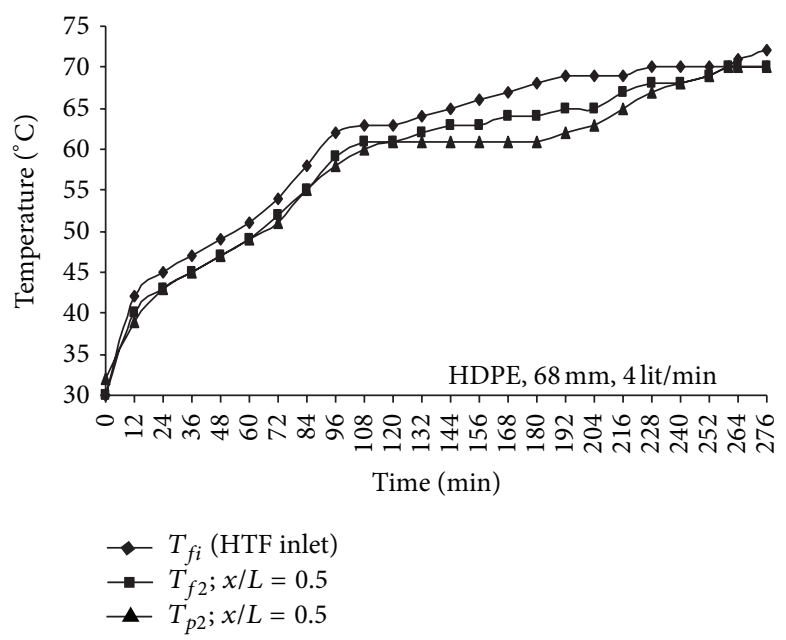

(c)

Figure 4: Temperature histories during charging process ( $m=4$ lit/min; paraffin). (a) HTF, (b) PCM, (c) HTF, and PCM.

are affected by the HTF flow rate. The Figure 5 shows that the time taken to reach the melting temperature of PCM is around $40 \%$ of the total time of charging. For the melting process of PCM, the time taken is around $30 \%$ and for heating from melting temperature to $70^{\circ} \mathrm{C}$, around $30 \%$ is taken. To rise the PCM temperature from melting temperature to $70^{\circ} \mathrm{C}$, it took around $30 \%$ of time even though the heat addition into the TES tank is less, because the absorption of the heat by HTF from solar flat plate collector at that temperature is not efficient, due to more heat losses from flat plate collector at that temperature.

Figure 6 shows the relationship between PCM temperature and charging time for different PCM capsule materials. During this experiment the HTF flow rate of $4 \mathrm{lit} / \mathrm{min}$ is maintained constantly between solar flat plate collector and TES tank for all types of capsule materials. The graphs show that for all the capsule materials the trend is the same throughout the charging period. The PCM temperature for aluminium and MS capsule is almost the same with maximum of $1^{\circ} \mathrm{C}$ difference throughout the charging period. The PCM temperature for HDPE capsules was maximum of $2^{\circ} \mathrm{C}$ difference with aluminium capsules.

3.1.3. Effect of Spherical Capsule Materials. The graphs show that the temperature difference between high thermal conductivity aluminium capsules and low thermal conductivity HDPE capsules is very low because the overall heat transfer coefficient between HTF and PCM is much influenced by the thermal conductivity of the PCM and diameter of the PCM spherical capsule but not by the thermal conductivity of PCM spherical capsule material. In the process of heat transfer from HTF to PCM, the thickness of the PCM capsule material (around $1.0 \mathrm{~mm}$ ) influences heat transfer coefficient only by around $5 \%$, because more thickness of the low thermal conductivity PCM within the capsule of diameter $68 \mathrm{~mm}$ has lot of influence on the heat transfer rate. With these results, we can conclude that the change of low cost HDPE PCM capsule material to high cost aluminium/MS PCM capsule material is 


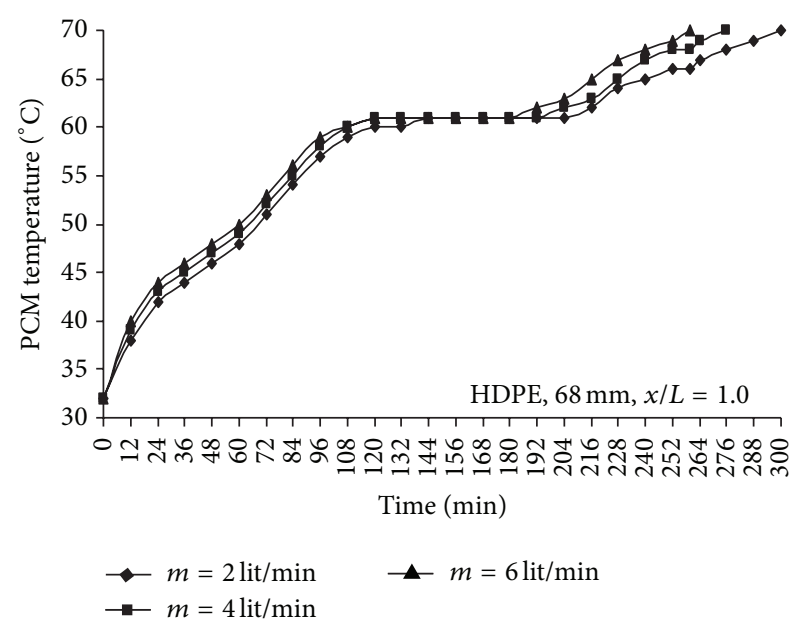

Figure 5: Effect of mass flow rate of HTF on charging time for varying $\mathrm{HTF}$ inlet temperature.

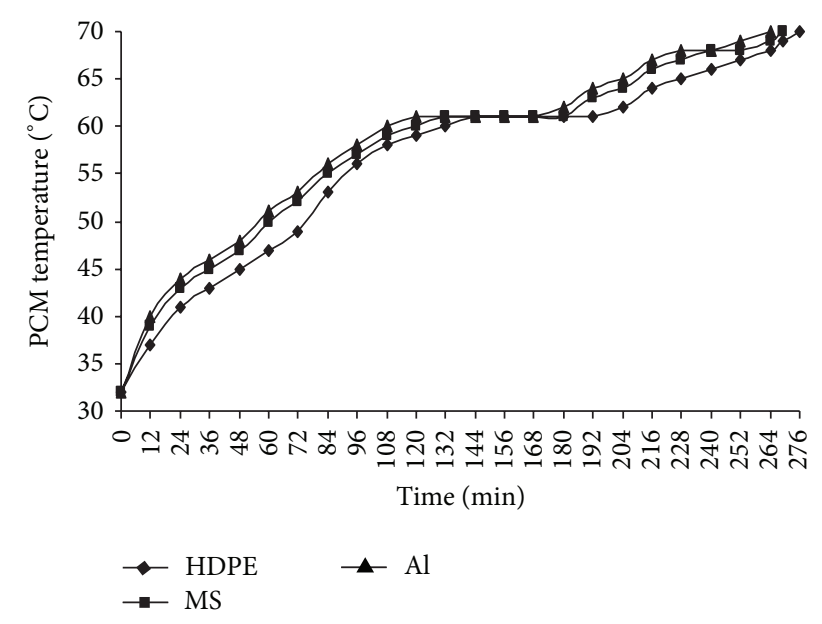

FIGURE 6: Effect of PCM spherical capsule materials on charging time for varying HTF inlet temperature.

not improving the performance of TES tank. Even though the thermal conductivity of aluminium is very high compared to HDPE/MS, because of the very low thickness of the capsule material, it only improves the heat transfer rate of the inner adjacent layer of PCM material, not the overall heat transfer rate.

3.2. Discharging Process. The discharging experiments are carried out by batchwise method. This method of discharge permits the complete utilization of heat in the storage tank. In the case of batchwise discharging process, a certain quantity (20 lit) of hot water is withdrawn from the storage tank and the same amount of cold water is filled in the storage tank. Withdrawn hot water is stored in the bucket having capacity of 20 lit and the average temperature of the hot water in the bucket is measured. The optimum retention period is 20 minutes between batches. The optimum retention time 20 minutes between batches is arrived by conducting a number

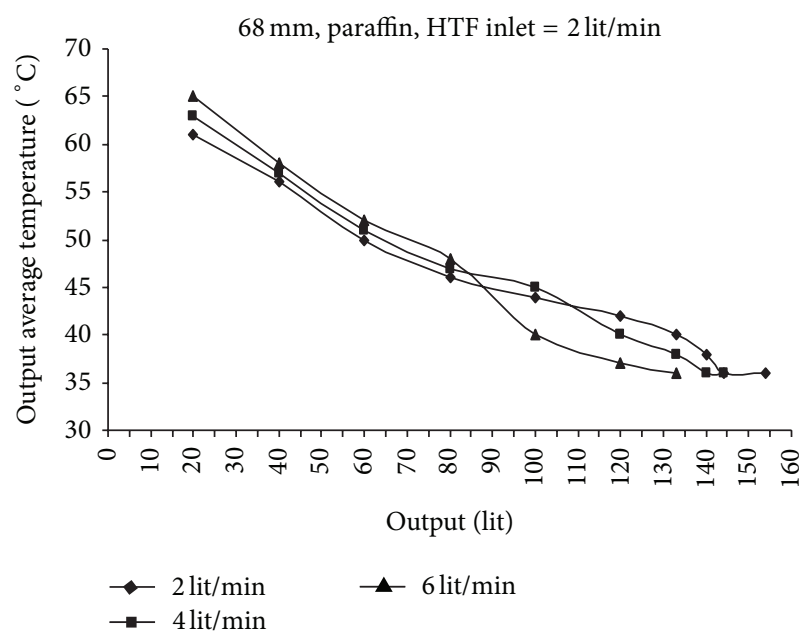

FIGURE 7: Variation of output (lit) for different flow rates for $68 \mathrm{~mm}$ diameter spherical capsule.

of experiments (with different retention times like 10, 15, 20, 25 , and 30 minutes). The batches of withdrawn hot water are continuous till the outlet temperature reaches $34^{\circ} \mathrm{C}$. The average temperature of the total withdrawn hot water is approximately $45 \pm 2^{\circ} \mathrm{C}$.

3.2.1. Effect of Flow Rate. Figure 7 shows the relationship between outlet water temperature and quantity of water output for different discharge flow rates $(2,4,6 \mathrm{lit} / \mathrm{min})$, even though the inlet HTF flow rate is constant, that is, 2 lit $/ \mathrm{min}$. The curves show that the average temperature of hot water outlet is more for 6 lit/min discharge and the total quantity of hot water outlet is less compared to the $2 \mathrm{lit} / \mathrm{min}$ and $4 \mathrm{lit} / \mathrm{min}$. This is mainly due to the low mixing of inlet water ( $2 \mathrm{lit} / \mathrm{min}$ to the tank) with stored water in TES tank. In the other two flow rates, that is, $2 \mathrm{lit} / \mathrm{min}$ and $4 \mathrm{lit} / \mathrm{min}$, the average temperature is low because of high mixing of inlet water. The mixing is high because the time taken for discharge of 20 lit per batch is more in the cases of 2 and $4 \mathrm{lit} / \mathrm{min}$.

3.2.2. Effect of Spherical Capsule Materials. Figure 8 shows the relationship between outlet water average temperature and discharge water output for different PCM spherical capsule materials. The curves show that the average temperature and output of hot water from TES tank are slightly more for the MS spherical capsules compared to HDPE/aluminium capsules, because the density of the MS capsules material is high and thereby the heat storing capacity is more. It means that the change of capsule material does not have much influence on the performance of the TES tank.

\section{Conclusions}

A thermal energy storage system has been developed for the use of hot water at an average temperature of $45^{\circ} \mathrm{C}$ for domestic applications using combined sensible and latent heat storage concept. Charging experiments are conducted 


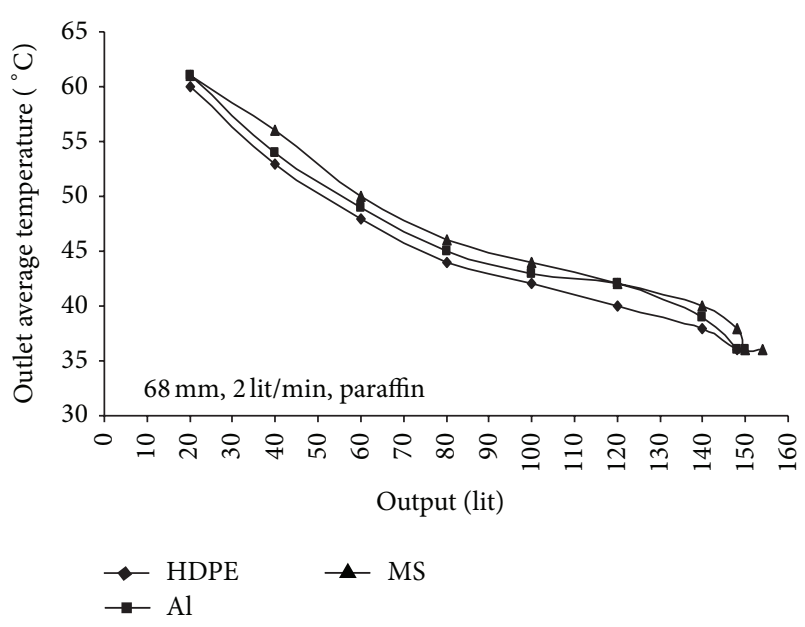

FIGURE 8: Variation of output (lit) for different spherical capsule materials.

on the TES unit to study its performance by integrating it with varying (solar) heat source. The temperature histories of HTF and PCM are studied during charging the process for paraffin (type II). Mass flow rate has significant effect on charging time. It is seen from the figure that the charging time is decreased by $24 \%$ when the mass flow rate is increased from 2 to $6 \mathrm{~kg} / \mathrm{min}$.

Also the investigation of the effect of PCM capsule material on the performance of TES tank while charging and discharging for variable (solar) heat source concludes that there is no appreciable performance improvement in the system by changing the capsule materials varying from low thermal conductivity $\left(\mathrm{HDPE}=0.52 \mathrm{w} / \mathrm{m}^{\circ} \mathrm{C}\right)$ to very high thermal conductivity (aluminium $=240 \mathrm{w} / \mathrm{m}^{\circ} \mathrm{C}$ ).

\section{Conflict of Interests}

The authors declare that there is no conflict of interests regarding the publication of this paper.

\section{References}

[1] M. M. Weislogel and J. N. Chung, "Experimental investigation of condensation heat transfer in small arrays of PCM-filled spheres," International Journal of Heat and Mass Transfer, vol. 34, no. 1, pp. 31-45, 1991.

[2] K. A. R. Ismail and J. R. Henríquez, "Numerical and experimental study of spherical capsules packed bed latent heat storage system," Applied Thermal Engineering, vol. 22, no. 15, pp. 17051716, 2002.

[3] U. Stritih, "An experimental study of enhanced heat transfer in rectangular PCM thermal storage," International Journal of Heat and Mass Transfer, vol. 47, no. 12-13, pp. 2841-2847, 2004.

[4] Y. Shiina and T. Inagaki, "Study on the efficiency of effective thermal conductivities on melting characteristics of latent heat storage capsules," International Journal of Heat and Mass Transfer, vol. 48, no. 2, pp. 373-383, 2005.

[5] H. Ettouney, I. Alatiqi, M. Al-Sahali, and K. Al-Hajirie, "Heat transfer enhancement in energy storage in spherical capsules filled with paraffin wax and metal beads," Energy Conversion and Management, vol. 47, no. 2, pp. 211-228, 2006.

[6] N. Nallusamy, "Effective utilization of solar energy for water heating applications using combined sensible and latent heat storage system," in Proceedings of the International Conference on New Millennium Alternate Energy Solutions for Sustainable Development, pp. 103-108, PSG Tech, 2003.

[7] E.-B. S. Mettawee and G. M. R. Assassa, "Thermal conductivity enhancement in a latent heat storage system," Solar Energy, vol. 81, no. 7, pp. 839-845, 2007.

[8] H. El Qarnia, "Numerical analysis of a coupled solar collector latent heat storage unit using various phase change materials for heating the water," Energy Conversion and Management, vol. 50, no. 2, pp. 247-254, 2009. 


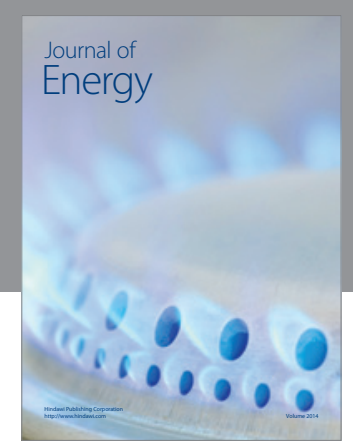

Journal of

Industrial Engineering
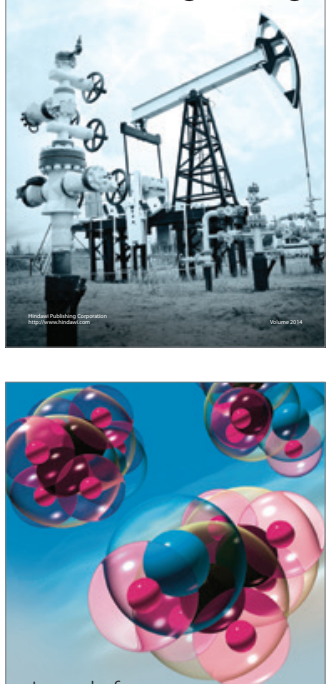

Fuels
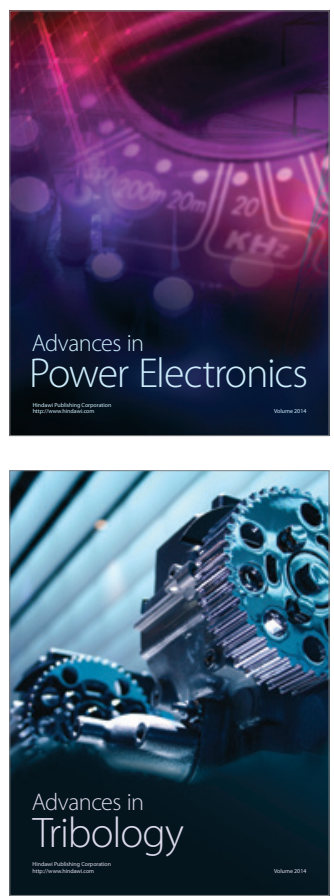

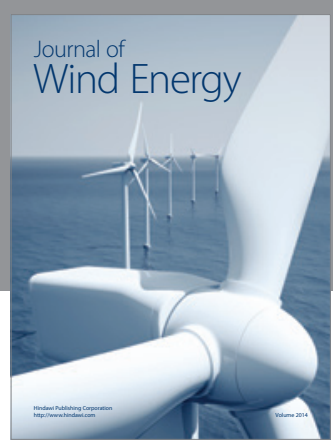

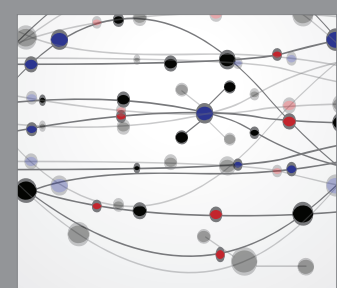

The Scientific World Journal

Submit your manuscripts at http://www.hindawi.com

Journal of

Structures
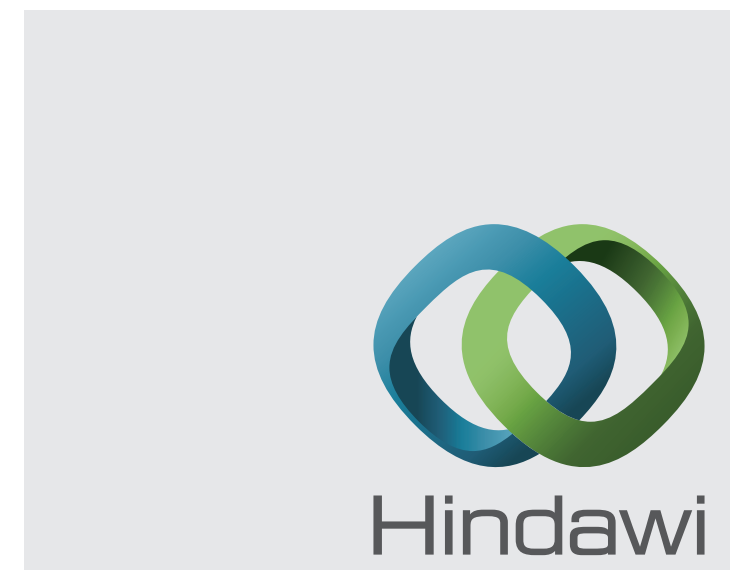

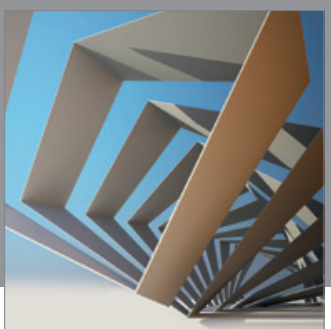

Rotating

Machinery
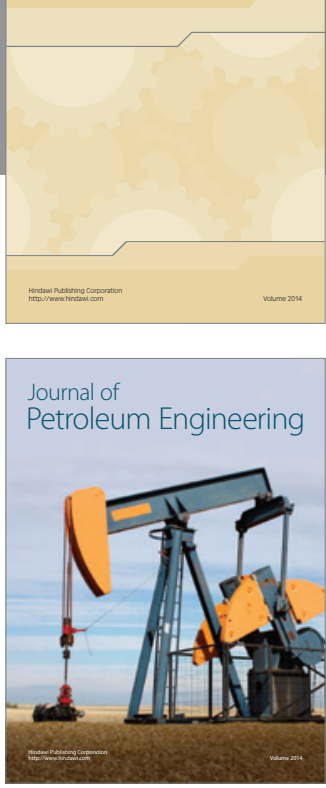

Journal of

Solar Energy
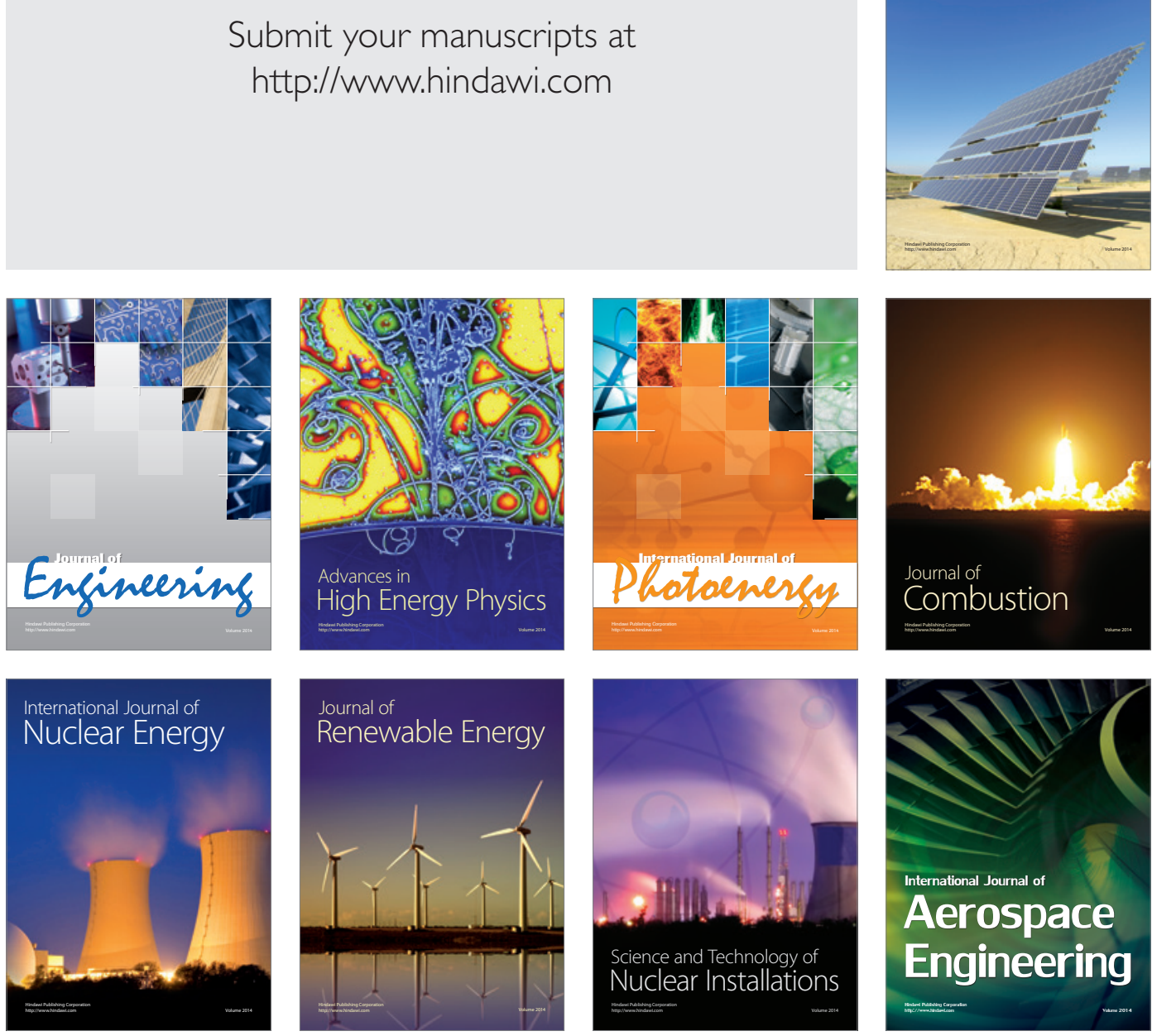